\title{
Management of Post-implant Complications: A Case Series
}

Meghna Nigam ${ }^{1}$, Vaibhav A Karemore ${ }^{2}$, Mangesh B Phadnaik ${ }^{3}$, Ripunjay Tripathi ${ }^{4}$, Ankit Solanki ${ }^{5}$, Samit Javiya $^{6}$, Sharad Agrawal ${ }^{7}$

\author{
Abstract \\ The increasing mean age of the population, and consequently edentulism, necessitates the demand for prosthesis. Owing to the drawbacks of \\ the removable partial denture and fixed partial denture, the implant as a treatment option has become popular. But with the use of implants, \\ complications are bound to occur. Management of these complications make implantology a success and thus, common complications are \\ discussed in this case series. \\ Keywords: Complication, Implants, Management. \\ International Journal of Oral Implantology and Clinical Research (2018): 10.5005/jp-journals-10012-1174
}

\section{INTRODUCTION}

The increasing mean age of the population, and consequently edentulism, necessitates the demand for prosthesis. Dental implants have become an everyday affair since the last decade for the treatment of lost teeth. According to a retrospective study by McDermott et al. ${ }^{1}$ an overall frequency of implant-related complications is $13.9 \%$.

With the advancement, implantology is at its boom and following are the related complications:

- Anatomy-related complications

- Treatment plan-related complications

- Procedure-related complications

- Early and late complications

- Mechanical complications

\section{Case Description}

Anatomy-related complications include nerve injury, bleeding, cortical plate perforation, sinus membrane perforation, and devitalization of adjacent teeth. This could be rectified by thoroughly investigating the radiograph and cone beam computed tomography.

\section{Case 1: Sinus Membrane Perforation}

The maxillary sinus floor elevation is a standard surgical procedure to rehabilitate severe vertical bone atrophies in the posterior maxilla by placement of osseointegrated implants. ${ }^{2}$ The most common complication of this procedure is the perforation of sinus membrane.

\section{Case Presentation}

A 48-year-old female reported to the Department of Periodontology for the replacement of missing teeth.

Clinical examination showed missing maxillary left first, second, and third molar. Since the patient wanted a fixed prosthesis, implant supported prosthesis was the only option.

\section{Treatment}

There was adequate buccolingual and mesiodistal width but the bone height was $6 \mathrm{~mm}$. So, a direct sinus lift and bone augmentation procedure with simultaneous implant placement was planned, during which perforation of the Schneiderian membrane occurred.

\footnotetext{
${ }^{1-4}$ Department of Periodontology, Government Dental College and Hospital, Nagpur, Maharashtra, India

${ }^{5}$ Private Practice, Mumbai, Maharashtra, India

${ }^{6}$ Department of Periodontology, Government Dental College and Hospital, Aurangabad, Maharashtra, India

${ }^{7}$ Private Practice, Raipur, Chhattisgarh, India

Corresponding Author: Meghna Nigam, Department of Periodontology, Government Dental College and Hospital, Nagpur, Maharashtra, India, Phone: +91 7666074854, e-mail: meghnanigam1515@gmail. com

How to cite this article: Nigam M, Karemore VA, et al. Management of Post-implant Complications: A Case Series. Int J Oral Implantol Clin Res 2018;9(1-3):24-29.

Source of support: Nil

Conflict of interest: None
}

\section{Management}

The original technique, known as "Loma Linda Pouch," ${ }^{3}$ consists of covering the whole sinus with a collagen membrane simulating the natural membrane, and the graft material is completely covered in its center by folding the membrane on the lateral wall. In this manner, an external barrier is created that totally isolates the biomaterial from the blood supply coming from the walls of the sinus, thus representing an obstacle to the maturation of the graft and the recovery process. ${ }^{4}$

The present case was managed by suturing the Schneiderian membrane with a 5-0 chromic gut resorbable suture followed by grafting with hydroxyappatite, DFDBA and placing a collagen membrane and simultaneous implant placement (Fig. 1).

Treatment plan-related complications include improper implant location and wrong angulation. This could be prevented by the use of surgical guides.

\section{Case 2: Improper Implant Angulation}

\section{Case Presentation}

A 45-year-old female patient was referred to the Department of Periodontology for implant-supported prosthesis with respect to 36. The buccolingual and the mesiodistal ridge dimensions were 

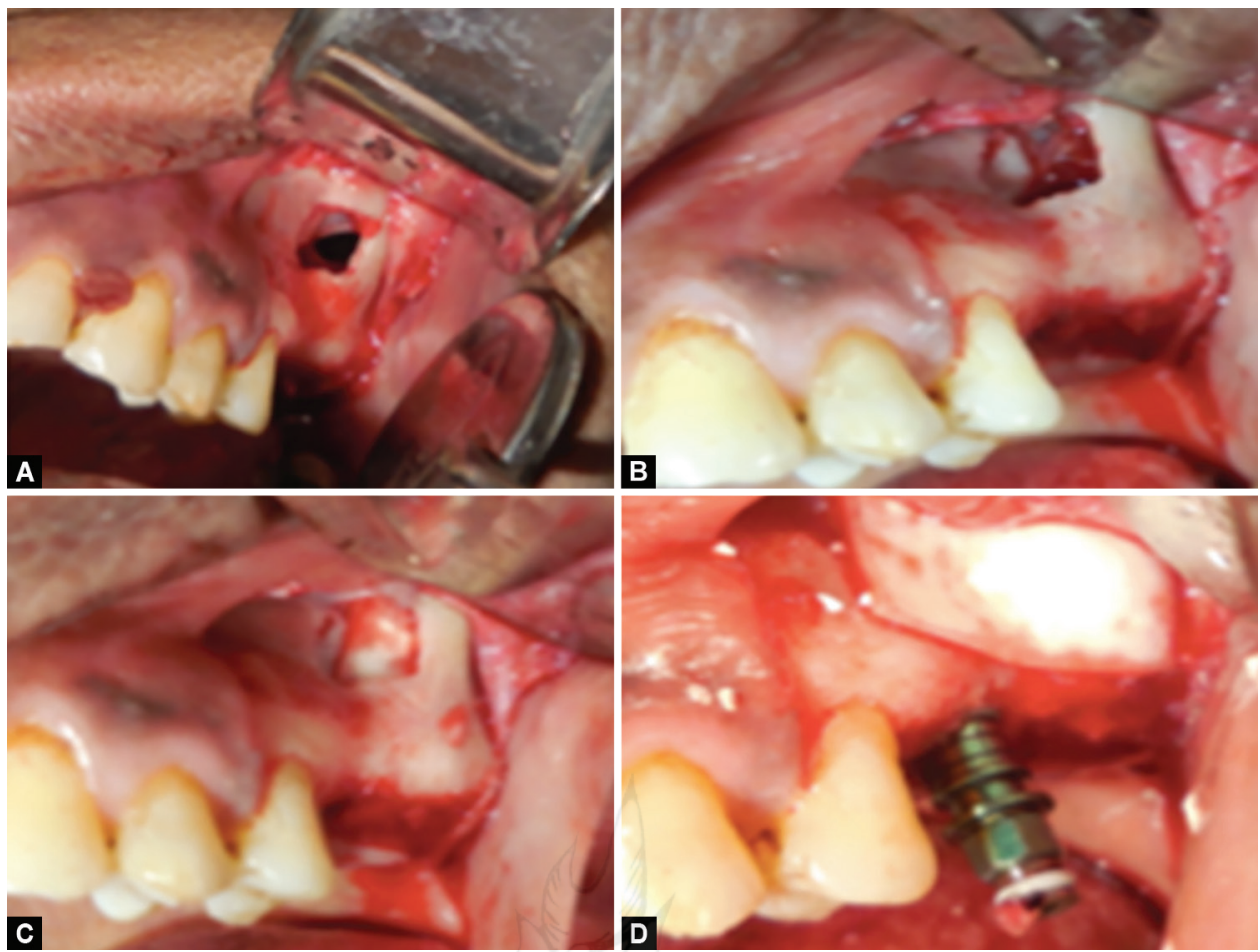

Figs 1A to D: Sinus membrane perforation. (A) Membrane perforation; (B) Suturing of the Schneiderian membrane; (C) Membrane placement; (D) Simultaneous implant placement with grafting and collagen membrane

$6.35 \mathrm{~mm}$ and $7.34 \mathrm{~mm}$, respectively, with a bone height of $11.3 \mathrm{~mm}$. The patient had idiopathic reduced mouth opening.

\section{Treatment}

The implant was placed correctly in the mesiodistal direction but had a slight buccal offset. This probably happened because of limited mouth opening, which makes the implant placement in mandibular posterior region difficult.

\section{Management}

Various options for management include premachined angled abutment, custom abutment with milled lingual screw hole, or a screw hole placed buccally. So a screw-retained prosthesis with a buccal screw access hole was given to the patient (Fig. 2).

Procedure-related complications include complications like lack of primary stability, mandibular fracture, ingestion and aspiration of implants etc. Achieving primary stability depends on many factors like bone quantity and quality, implant design, etc. Prevention of

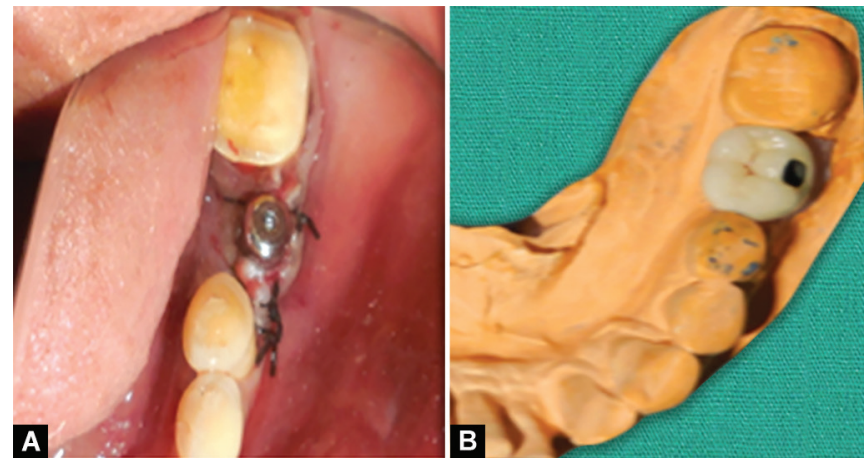

Figs $2 \mathrm{~A}$ and B: Improper implant angulation. (A) Buccally placed implant; (B) Prosthesis fabricated with buccal access screw hole ingestion and aspiration of implant surgical drills etc. can be done by the use of a rubber dam. Mandibular fractures are common if implants are placed in severe atrophic mandible.

Early and late complications include edema, bleeding, ecchymosis and hematoma, emphysema, mucosal dehiscence, implant fracture, and peri-implant complications. Atraumatic surgical techniques minimize tissue damage, while the application of ice packs and the administration of corticosteroids will prevent or limit edema and risk of ecchymosis after implant surgery.

\section{Case 3: Soft Tissue Dehiscence}

Wound dehiscence is a soft tissue complication that can develop infections post surgery. As a rule, surgical wound dehiscence is associated with patients who have a thin gingival biotype.

Another factor leading to surgical wound dehiscence is flap closure under tension, for a higher tension causes a more frequent onset of these complications (Lee and Thiele). ${ }^{5}$ The prevalence of incisional line opening ranges from $4.6 \%$ to $40 \%$ around the submerged implants.

\section{Case 3 Presentation}

A 52-year-old female reported to the OPD with the complaint of multiple mobile teeth. Examination revealed generalized severe chronic periodontitis with hopeless prognosis of $36,35,34,33,32$, $31,41,42,43,44,45$, and 46.

\section{Treatment}

The teeth with the hopeless prognosis were extracted followed by delayed implant placement. The placement of implants in mandibular anterior was done after the ridge split technique. Suturing was done after giving periosteal releasing incision and coronal advancement of flap. At the appointment of suture removal, 
wound dehiscence was seen in the mandibular anterior region. So, the creation of fresh wound margins and suturing was done. Post suturing, there was closure in the incision line (Fig. 3).

\section{Case 4: Peri-implant Bone Loss}

Peri-implant infections are generally classified as peri-implant mucositis and peri-implantitis depending on the severity. Periimplant mucositis is defined as a reversible inflammatory reaction in the soft tissues surrounding an implant. Peri-implantitis is an inflammatory reaction with loss of supporting bone in the tissues surrounding an implant. ${ }^{6}$

\section{Case Presentation}

A 62-year-old male reported to the department with the complaint of missing teeth. Examination showed missing 36 with buccolingual and mesiodistal dimensions of $6.5 \mathrm{~mm}$ and $10.7 \mathrm{~mm}$, respectively.

\section{Treatment}

A single-stage implant was placed in the 36 region. When the patient was recalled after 3 months for prosthetic rehabilitation, there was grade I mobility with the implant. On taking the intraoral periapical radiograph, angular bone loss was noted in coronal one-third of the implant.

\section{Management}

This was managed with a regenerative procedure. After flap reflection, debridement was done, followed by DFDBA and chorion membrane placement. Instead of placing gingival former again, cover screw was placed and the patient was recalled after 6 months. There was a decrease in radiolucency and complete absence of mobility after 6 months. Then, healing abutment was placed followed by impression and prosthesis (Fig. 4).

Mechanical complications are overdenture-related complications, fracture of fixed restoration, dislodgement of gingival
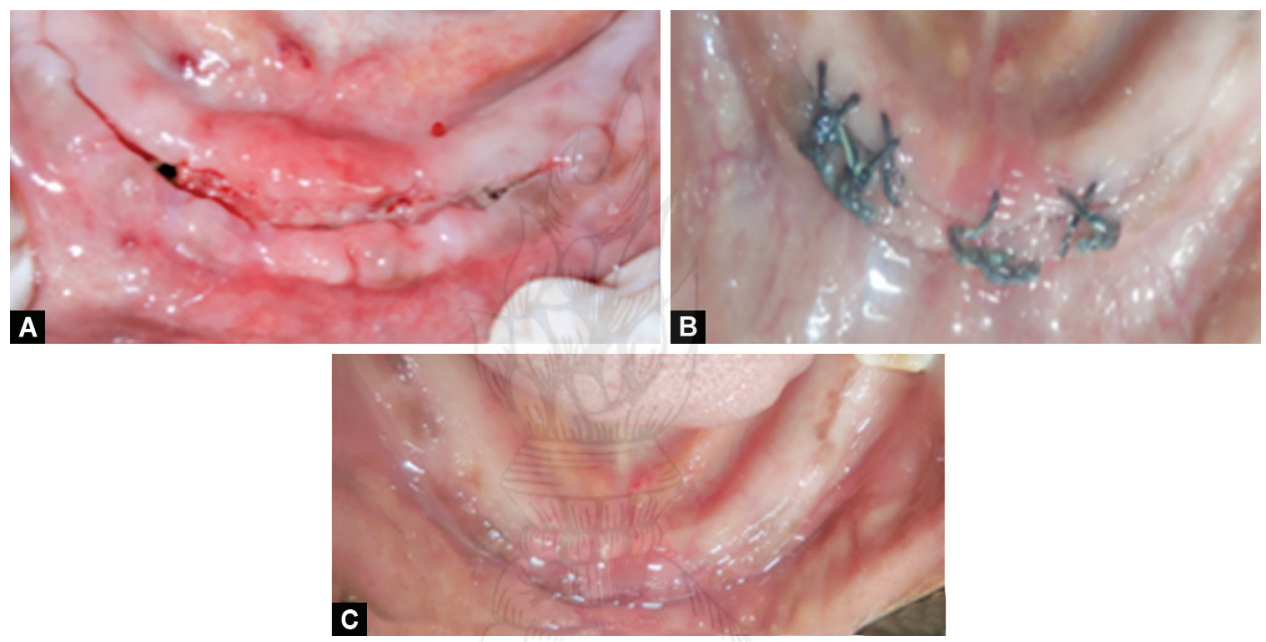

Figs 3A to C: Soft tissue dehiscence. (A) Dehiscence of the wound margin; (B) Suturing of the wound margins after creating fresh wound edge; (C) 15 days postsuture removal
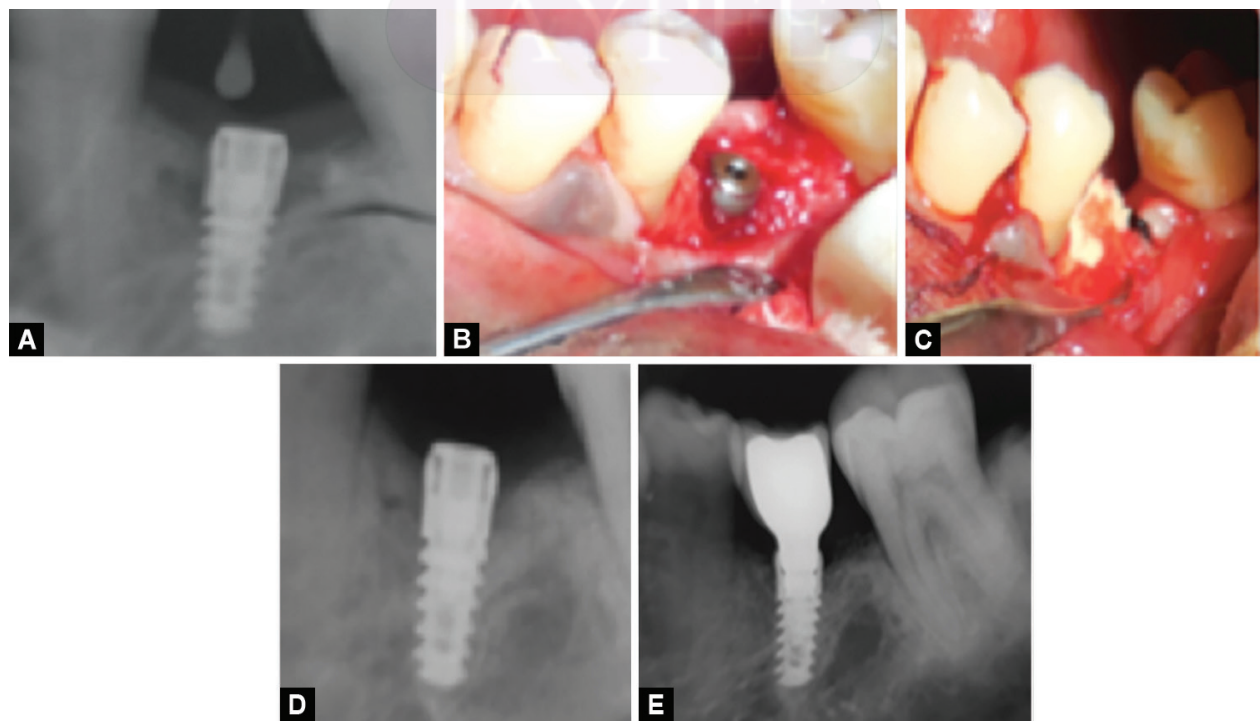

Figs 4A to E: Peri-implant bone loss management. (A) Radiolucency in coronal third of the implant; (B) Flap reflection and debridement; (C) Grafting with DFDBA and chorion membrane placement; (D) Decreased radiolucency around implant; (E) 6 months postprosthesis delivery 

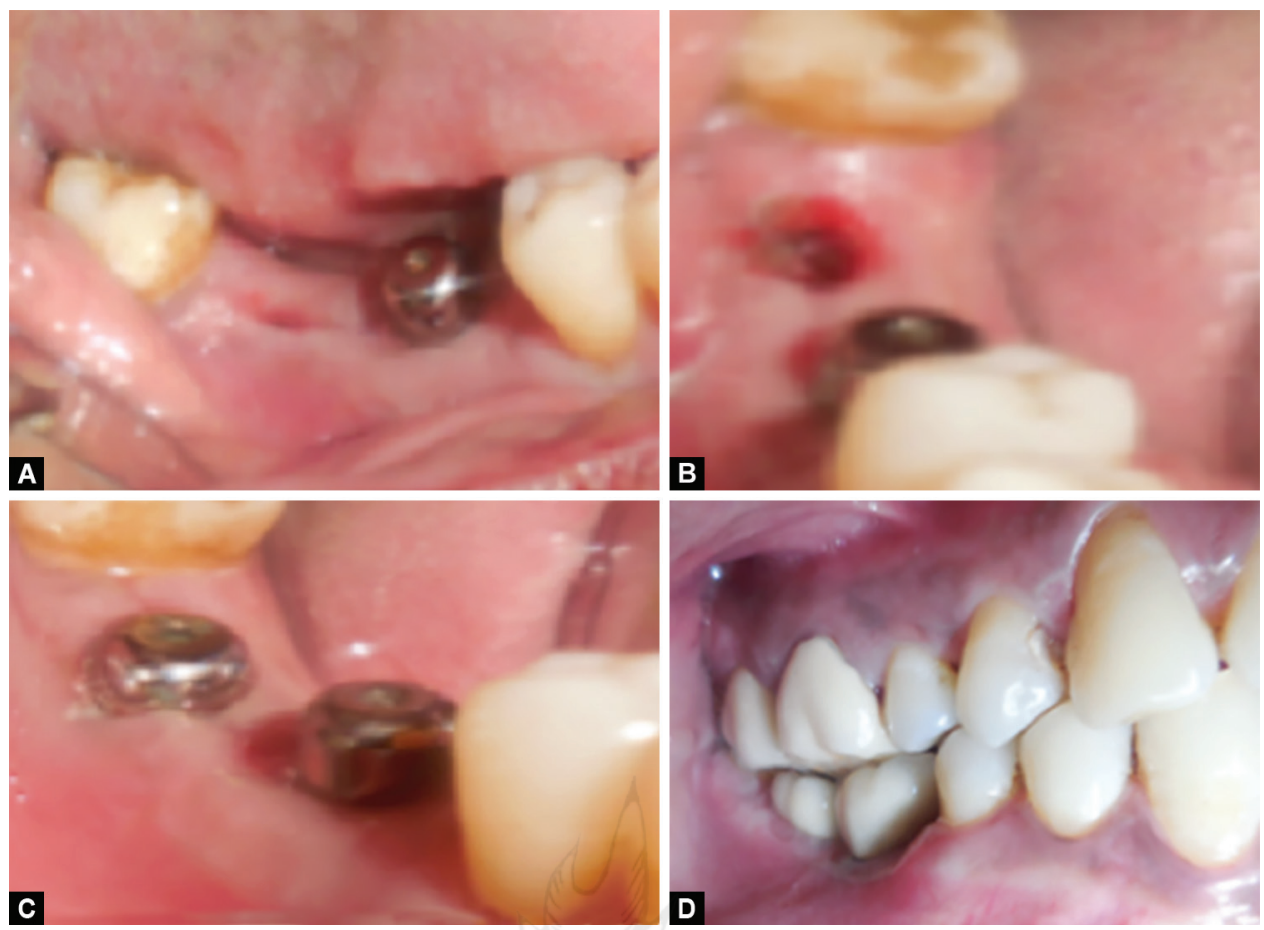

Figs 5A to D: Dislodged gingival former. (A) Dislodged gingival former in 47; (B) Diode laser used to expose the implant platform; (C) The former placed in position; (D) Prosthesis placed

former, implant screw related complications, etc. Prevention of overdenture-related complications is achieved by incorporating cast chromium-cobalt framework reinforcement in the denture base in implant-retained mandibular overdentures that address the problem associated with the fracture of denture base.

\section{Case 5: Dislodged Gingival Former}

Traditionally, scalpel blade or tissue punch has been utilized to incise the soft tissue to expose the implant for the restorative phase. ${ }^{7}$ This delays the postoperative healing for impression making.

An alternative to the scalpel and blade are electrosurgery, ${ }^{8}$ diode laser, ${ }^{9}$ etc., which can be used to expose the implant.

Diode lasers, as an alternative, can modify soft tissue around the dental implant for uncovering the gingival margin within the temperature range so that negative effects do not occur to the bone around the implant.

The width of the attached remaining gingiva will dictate how the implant is uncovered. When a wide band of attached gingiva is present ( $3 \mathrm{~mm}$ ideally) the diode laser is used. Sites where less attached gingiva is present, a conventional flap is recommended to be able to position the tissue in a more apical direction.

\section{Case Presentation}

A 38-year-old male patient was treated with an implant placement in the 36 region.

\section{Treatment}

At the stage II implant surgery, gingival former was placed. The patient reported with a dislodged gingival former 10 days after performing stage II.

\section{Management}

As the width of attached gingiva was adequate, diode laser was used to uncover the implant and place the former back again.
Further, impressions were made and prosthesis was delivered (Fig. 5).

\section{Case 6: Fractured Abutment Implant SCREW}

Kreissl et al. found the incidence of abutment screw fracture to be 3.9 percent and that of screw loosening to be at 6.7 percent. $^{10}$

There may be various reasons for the abutment screw fracture. This can be managed by different techniques-they can be retrieved with the help of scalers, ${ }^{11}$ small round bur and handpiece, ${ }^{11}$ and reverse tapping rotary instruments. ${ }^{12}$

\section{Case Presentation}

A 48-year-old female reported to the OPD with a complaint of missing mandibular left first molar. Clinical examination revealed buccolingual and mesiodistal widths of $7.6 \mathrm{~mm}$ and $11.13 \mathrm{~mm}$, respectively. The bone height was $10 \mathrm{~mm}$. Implant-supported prosthesis was given with respect to 36 . The patient reported screw loosening 3 months later.

\section{Treatment}

Further examination revealed fracture of the abutment screw. On eliciting the history, the patient revealed about screw loosening 2 days prior reporting to the department but she couldn't report immediately which must have eventually led to the screw fracture due to occlusal forces.

\section{Management}

The scaler tip and curettes were used. The scaler's vibratory motion was used to vibrate the screw while curette was used to rotate the screw anticlockwise. This finally resulted in the screw retrieval (Fig. 6). 

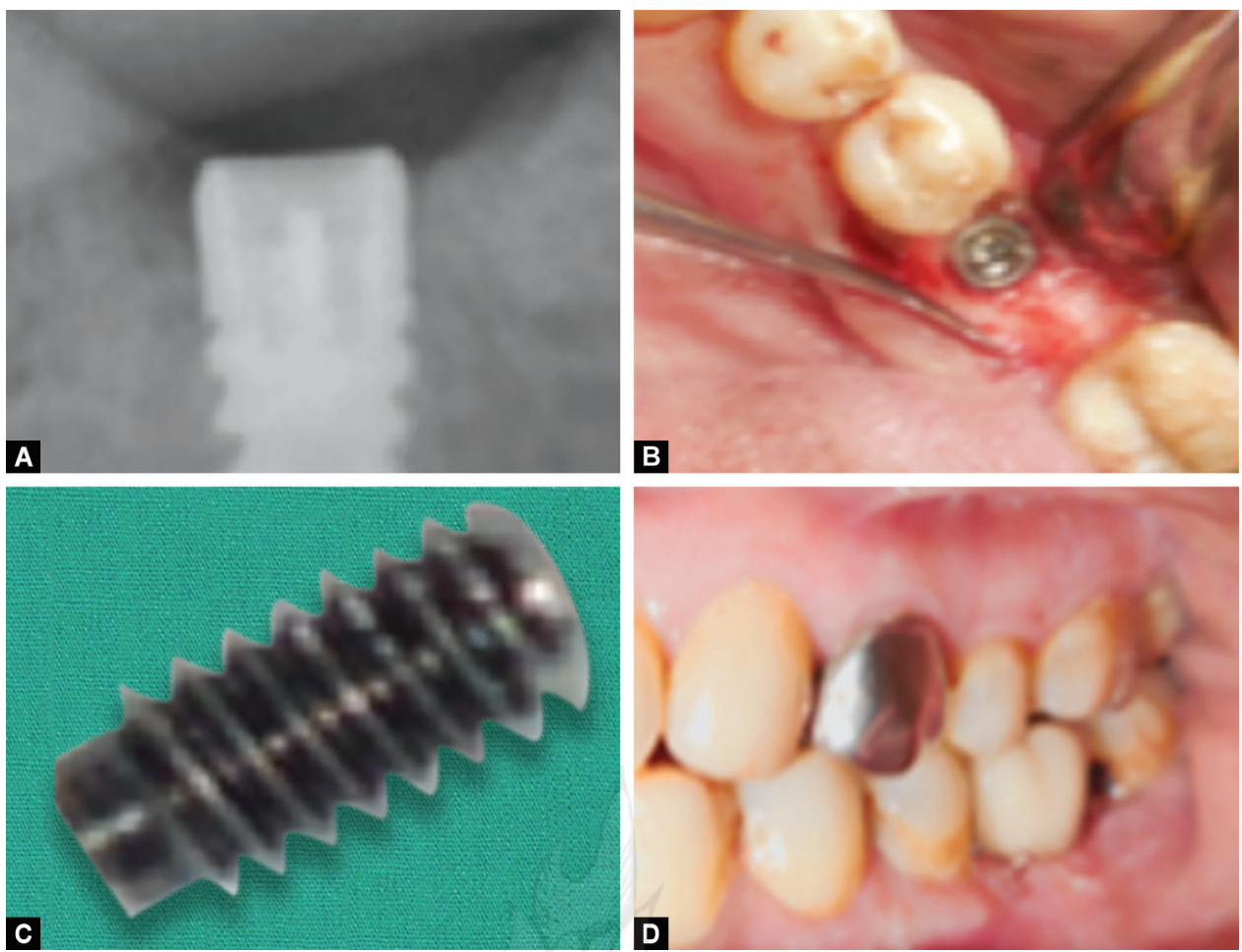

Figs 6A to D: Fractured abutment implant screw. (A) Radiograph showing fractured abutment screw; (B) Mucoperiosteal flap reflected; (C) Retrieved fractured screw; (D) Prosthesis placed back

\section{Discussion}

With respect to the above-mentioned complications, a light is thrown upon the possible etiologies and ways to prevent them.

For preventing sinus perforation, following points should be remembered: $:^{13}$ (1) adequate screening of the sinus and predetermining the sinus health, (2) presence of sinus septae, oblique sinus floor, and widened sinus are anatomical concerns that increase the risk of sinus perforation, (3) in posterior maxilla with poor bone quality, undersized drilling technique should be considered to improve primary stability and (4) use of adjustable stops on osteotomes when infracturing the sinus floor to limit apical penetration. But in spite of the best precautions, perforations can happen and perforation repair is always an option.

For placing the implants in accurate position, surgical guides should be used. One reason for buccal offset can be the use of finger rest while placing an implant. Using finger rests is an ergonomic principle that should not be used for implant placement. ${ }^{14}$

Time required for the wound healing is related to the gap between tissue wound margins. Therefore, perfect adaptation will allow earlier suture removal and prevent incision line opening. Wound support is only needed until the healing process has progressed to such an extent that the tissue can withstand functional forces. ${ }^{15}$

Peri-implant bone loss at stage II may occur occasionally due to crestal bone trauma during surgery, excess torque from implant insertion, etc. Depending on the amount of bone loss, various treatments can be rendered. For vertical bone loss, if defect depth is $<3 \mathrm{~mm}$ osteoplasty can be done and if vertical defect depth $>3 \mathrm{~mm}$, grafting and use of barrier membrane is advocated. ${ }^{16}$

Dislodging the gingival former results in the closure of the implant access hole many a times. But uncovering the implant and placing it again requires either of the 2 approaches-laser or scalpel. Precaution to minimize the chances of dislodgement of the former requires torqueing the healing abutment at $10 \mathrm{~N} \mathrm{~cm} .{ }^{16}$

Management of screw fracture is difficult many a times. Various causes for screw loosening and subsequent screw fracture are excursive contact, off-axis centric contacts (angled abutments or wide occlusal table), interproximal contacts, cantilever contacts, etc. ${ }^{17}$ So utmost care needs to be taken to check all these factors.

\section{Conclusion}

With the advent of implantology as an emerging prosthetic option in dentistry, complications are also increasing day by day. So, the success of an implantologist does not lie in just the placement of implant but it lies also in managing the complications.

\section{References}

1. McDermott N, Chuang S, et al. Complications of dental implants: Identification, frequency, and associated risk factors. Int J Oral Maxillofac Implants 2003;18:848-855.

2. Boyne PJ, James RA. Grafting of the maxillary sinus floor with autogenous marrow and bone. J Oral Surg 1980;8:613-616.

3. Proussaefs P, Lozada J. The "Loma Linde Pouch". A technique for repairing the perforated sinus membrane. Int J Periodontic Restorative Dent 2003;23:593-597.

4. Fugazzotto PA, Vlassis J. A simplified classification and repair system for sinus membrane perforations. J Periodontol 2003 Oct;74(10):15341541. DOI: 10.1902/jop.2003.74.10.1534.

5. Lee $\mathrm{S}$, Thiele $\mathrm{C}$. Factors associated with free flap complications after head and neck reconstruction and the molecular basis of fibrotic tissue rearrangement in preirradiated soft tissue. J Oral Maxillofac Surg 2010;68(9):2169-2178. DOI: 10.1016/j.joms.2009.08.026. 
6. Albrektsson T, Isidor F. Consensus report of session IV. In: Lang NP, Karring T. ed. Proceedings of the first European Workshop on Periodontology. London: Quintessence; 1994. pp. 365-369.

7. Zetz MR, Quereshy FA. Single-stage implant surgery using a tissue punch. J Oral Maxillofac Surg 2000 Apr;58(4):456-457. DOI: 10.1016/ S0278-2391(00)90937-6.

8. Wilcox CW, Wilwerding TM, et al. Use of electrosurgery and lasers in the presence of dental implants. Int J Oral Maxillofac Implants 2001 Jul-Aug;16(4):578-582.

9. Gherlone EF, Maiorana C, et al. The use of an 980-nm Diode and $1064 \mathrm{~nm}$ Nd:YAG Liaser for Gingival Retraction in Fixed Prosthsis. J Oral Laser Appl 2004:4:183-190.

10. KreissI ME, Gerds T, et al. Technical complications of implantsupported fixed partial denture in partially edentulous cases after an average observation period of 5 years. Clin Oral Implants Res 2007;18:720-726. DOI: 10.1111/j.1600-0501.2007.01414.x.

11. Christensen GJ. Clinical tip: How to easily remove broken abutment screws in dental implants. Dentistry IQ, Guide for Preferred Clients Jul/Aug 2010, Vol. 15(4).
12. Yoon $\mathrm{JH}$, Lee $\mathrm{H}$, et al. Safe removal of a broken abutment screw with customized drill guide and rotary instrument: A clinical report. J Prosthodont 2016;25(2):170-173.

13. Toffler M, Rosen PS. Complications with transcrestal sinus floor elevation: etiology, prevention, and treatment. Dent Implant Compl Etiol Prev Treat 2015 Nov 16; 427-456.

14. Misch K, Wang $\mathrm{HL}$. Implant surgery complications: etiology and treatment. Implant Dent 2008 Jun 1;17(2):159-168. DOI: 10.1097/ ID.0b013e3181752f61.

15. Velvart $\mathrm{P}$, Peters $\mathrm{Cl}$. Soft tissue management in endodontic surgery. J Endod 2005 Jan 1;31(1):4-16.

16. Misch CE. Stage II Surgery: Uncovery and Treatment of Healing Complications. In: Misch CE. ed. Contemporary Implant Dentistry, 3rd ed., Ch 32, Mosby Year Book; 2008. pp. 720-738.

17. Brägger $U$, Aeschlimann $S$, et al. Biological and technical complications and failures with fixed partial dentures (FPD) on implants and teeth after four to five years of function. Clin Oral Implants Res 2001 Feb;12(1):26-34. DOI: 10.1034/j.1600-0501.2001. 012001026.x 